\title{
A study of the sea-salt chemistry using size-segregated aerosol measurements at coastal Antarctic station Neumayer
}

\author{
K. Teiniläa,*, A. Frey ${ }^{\mathrm{a}}$, R. Hillamo ${ }^{\mathrm{a}}$, H. C. Tülp ${ }^{\mathrm{b}, \mathrm{c}}$, R. Weller ${ }^{\mathrm{b}}$ \\ ${ }^{a}$ Finnish Meteorological Institute, Atmospheric Composition Research, Erik Palménin aukio \\ 1, FIN-00560, Helsinki, Finland \\ ${ }^{b}$ Alfred-Wegener-Institut Helmholtz-Zentrum für Polar- und Meeresforschung, Am \\ Handelshafen 12, 27570 Bremenhaven, Germany \\ ${ }^{c}$ presently at British Antarctic Survey, High Cross, Madingley Road, Cambridge, CB3 OET, \\ United Kingdom
}

\begin{abstract}
Aerosol chemical and physical properties were measured in 2010 at Neumayer research station, Antarctica. Samples for chemical analysis (ion chromatography) were collected using a Teflon/Nylon filter combination (TNy) sampler, and with a multi stage low pressure impactor (SDI). Particle number concentration was measured continuously with a Grimm OPC optical particle counter. Total particle number concentration varied largely throughout the year, and the highest number concentrations for particles larger than $0.3 \mu \mathrm{m}$ were observed simultaneously with the highest sea salt concentrations. About $50 \%$ of the sea salt aerosol mass was found in the submicron size range. Below $0.2 \mu \mathrm{m}$ of particle aerodynamic diameter the contribution of sea salt aerosols was negligible. Further analysis showed that sea salt aerosols had undergone physicochemical processes, either during the transportation, or during their formation. High degree of chloride depletion was observed during austral summer, when the presence of acidic gases exhibit their characteristic seasonal maximum. Apart from chloride depletion, excess chloride relating to sodium was also detected in one SDI sample, indicating actually a sodium depletion by mirabilite formation
\end{abstract}

\footnotetext{
* corresponding author

Email address: kimmo.teinila@fmi.fi (K. Teinilä)
} 
on freshly formed sea ice areas. Analysis of selected episodes showed that the concentration of sea salt particles, their modal structure, and their chemical composition is connected with their source areas, their formation mechanisms, and local transport history.

Keywords: Antarctica, sea salt modification, mass size distribution, particle number concentration

\section{1. Introduction}

2 Antarctica is geographically isolated from anthropogenic particle sources,

3 therefore, the majority of measured particulate matter is of natural origin. Mi-

4 nor local anthropogenic sources comprise some emissions from research stations

5 associated transportation. Excluding minor areas free of snow and ice occasio-

- nally producing crustal particles, the majority of particulate matter is originated

7 from the nearby ocean (Wagenbach et al. 1998; : Minikin et al. 1998; Rankin and

$s$ Wolff, 2003; Weller and Wagenbach, 2007). Primary sea salt aerosol is the major

9 particulate matter (in mass) most time of the year (Weller et al. 2011). During

10 austral summer secondary sulphate aerosol produced from biogenic precursor

11 gases from the nearby ocean makes a substantial contribution to the particulate

12 mass, and in the submicron size range sulphate aerosol is even the dominant one

13 (Weller et al. 2011, Rankin and Wolff, 2003). While sulphate particles produced

14 via gas to particle conversion are mainly found in the submicron size range, sea

15 salt particles are spread over the size spectrum from $0.1 \mu \mathrm{m}$ up to $10 \mu \mathrm{m}$.

16 Sea salt particles are produced mechanically either over ice free ocean by 17 bubble bursting, or over freshly formed sea ice (Wolff et al. 2003, Rankin et al.

18 2000, Hall and Wolff, 1998). The chemical composition of aerosol particles pro-

19 duced from sea spray is similar to the sea water composition. On the contrary,

20 the physico-chemical processes forming frost flowers over the freshly formed sea

21 ice alter the chemical composition of sea salt particles. Most important of the-

22 se processes is the depletion of sulphate, and to lesser extent the depletion of 23 sodium compared to the sea water composition (Hall and Wolff, 1998). Once 

53 2003, Jourdain and Legrand, 2002, Kerminen et al., 2000, Teinilä et al., 2000.

54 Hillamo et al. 1998). Here we present results from size-segregated aerosol mea-

formed the sea salt particles further undergo physical and chemical processes during their transportation. The sea salt mass size distribution alters during the transport process due to the deposition of larger sea salt particles. The most important chemical process, which especially aged sea salt particles have undergone, is the reaction of sodium chloride with acidic gases, including $\mathrm{HNO}_{3}$ and $\mathrm{H}_{2} \mathrm{SO}_{4}$, which release $\mathrm{HCl}$ to the air and is the cause of chloride depletion in sea salt particles (Kerminen et al., 2000, Minikin et al., 1998, Wagenbach et al. 1998).

Using bulk filter samples impedes assessing the extent of different physicochemical processes modifying sea salt particles. For example, sulphate measured from filter samples may have originated from secondary sulphate particles externally mixed with sea salt, or may be secondary sulphate produced on sea salt particles.

The sulphate content of sea salt particles also alters due to their formation processes. In addition to the sulphate depletion, a minor amount of sodium may have also been depleted when sea salt particles are formed on the sea ice (Wolff et al. 2003, Rankin et al., 2000, Hall and Wolff, 1998).

Chloride depletion typically takes place throughout the year, but the degree of chloride depletion varies largely throughout the year, and over particle size. During austral summer, when production of acidic gases is enhanced, chloride depletion is in its maximum. Chloride depletion may also take place for collected particles on the filter, which may lead to overestimation of chloride depletion.

Cascade impactors size segregate the sampled particles onto collection substrates where their exposure to acidic gases is minimized and are, hence, the method of choice (Pakkanen and Hillamo, 2002).

Earlier studies of sea salt chemistry from bulk filter measurements include (Weller et al., 2008, Weller and Wagenbach, 2007, Hara et al., 2005, 2004, Wagenbach et al., 1998, Wolff et al., 1998), and from size-segregated aerosol measurements (Jourdain et al., 2008; Virkkula et al., 2006, Rankin and Wolff, 3 
55

surements at the coastal Antarctic station Neumayer (NM), and address the different physico-chemical processes altering particle composition. We will focus on sea salt particles, discussing the seasonality of the observed size distributions, and especially aim at assessing the size dependence sea salt chemistry. Further analysis of the size distributions of methane sulphonate $\left(\mathrm{MSA}^{-}\right)$and nitrate have been excluded due to possible artefacts in the SDI and TNy samplers.

\section{Experimental}

Aerosol measurements were made at the Air Chemistry Observatory, NM Station $\left(70^{\circ} 39^{\prime} \mathrm{S}, 8^{\circ} 15^{\prime} \mathrm{W}\right)$ between February 16 and December 8, 2010. Particle number concentration was measured using a Grimm Optical Particle Counter (OPC, model 1.108). The flow rate of the Grimm OPC is $1.2 \mathrm{~L} \mathrm{~min}^{-1}$, and the detection wavelength is $685 \mathrm{~nm}$. The Grimm OPC measures particles in 15 size bins between 0.3 and $20 \mu \mathrm{m}$. Averaging time of the Grimm OPC measurements was 10 minutes.

Size-segregated aerosol samples for chemical analysis were collected using a small deposit area impactor (SDI, Maenhaut et al. (1996)). Polycarbonate films coated with Apiezon-L vacuum grease were used as particle impaction substrates (poreless film from Nuclepore Inc., thickness $10 \mu \mathrm{m}$ ) in the SDI. The SDI has 12 collecting stages over the particle diameter range 0.045-20 $\mu \mathrm{m}$. At the pressure of 1013 mbar, and at the temperature of $23{ }^{\circ} \mathrm{C}$, the aerodynamic cut-off diameters of the individual SDI stages are equal to $0.045,0.086,0.153,0.231,0.343,0.591$, $0.796,1.06,1.66,2.68,4.08$, and $8.50 \mu \mathrm{m}$. The flow rate of the SDI impactor is 11

$\mathrm{L} \mathrm{min}^{-1}$. For chemical analysis particles were collected also on a Teflon/Nylon filter combination, (TNy, Jones et al. (1999)). The air samples for the SDI and TNy were taken directly from the common inlet duct. The cut-off of the inlet depends on the wind velocity. The tests with a TSI-APS 3321 showed that the cut-off is broadly around $7 \mu \mathrm{m}$. The SDI and TNy filter sampling systems were housed within the NM Air Chemistry Observatory (for a detailed description of the sampling site, meteorological conditions, contamination free sampling, 
84

and analysis of the samples we refer to Wagenbach et al. (1988), König-Langlo et al. (1998), Weller et al. (2008)). With a two-stage filter system including an upstream teflon (Millipore, $47 \mathrm{~mm}$ diameter, $1 \mu \mathrm{m}$ pore size), and a downstream nylon filter (Gelman Nylasorb, $47 \mathrm{~mm}$ diameter, $1 \mu \mathrm{m}$ pore size), roughly $60 \mathrm{~m}^{3}$ of air was typically sampled over a 24 hour collection period. The teflon filter collects all particulate compounds with efficiencies higher than $95 \%$, but allows gaseous (acidic) species like $\mathrm{HCl}$ and $\mathrm{HNO}_{3}$ to pass through as becoming partly absorbed on the nylon filter (Piel et al., 2006). Note, however, that we did not analyse teflon and nylon filters separately, but refer to total concentrations of these species.

Sampling time for the SDI samples were typically 7-8 days, but there were long breaks for the SDI samplings during September and October. The collection time for the TNy samples were typically 24 hours (sometimes 2 days), and the sampling usually started near midday. Total of 29 SDI samples were collected during the measurement campaign, but four of them were discarded from later analyses due to problems during the samplings.

Meteorological parameters like temperature, pressure, relative humidity, wind speed, and direction were available from the meteorological weather station. Ten day backward trajectories (arrival time 12:00) were calculated using a HYSPLIT4 model (Draxler and Hess, 1998). Used meteorological data was GDAS, $1^{\circ}$ resolution, and three dimensional calculation was made using vertical wind velocities. Starting height of the calculations was $500 \mathrm{~m}$ above sea level.

The samplings were controlled in case of contamination from station activities by wind velocity, wind speed, and by the condensation particle counter (Weller et al. 2008). In case of contamination the samplings were interrupted. Aerosol samplings were switched off also during harsh weather condition like blizzards and drifting snow in order to avoid snow entering the inlet.

Collected SDI samples were analysed in the Finnish Meteorological Institute (FMI) aerosol laboratory. SDI substrates were dissolved into $5 \mathrm{~mL}$ of deionized water and stirred about 10 minutes. The anions and cations were analysed simultaneously with two Dionex ICS-2000 ion chromatograph systems. The anion 

136 1998).

137

analysis was made using AG17/AS17 columns with an ARS-300 suppressor and a $\mathrm{KOH}$ eluent generator (gradient run, 1-25 mmol $\mathrm{L}^{-1}$ ). The cation analysis was made using CG12A/CS12A columns with a CSRS-300 suppressor and a methane sulphonic acid eluent generator (isocratic run, $25 \mathrm{mmol} \mathrm{L}^{-1}$ ). Detection of the ions were made using a conductivity detector. The run time was 14 minutes. Analysed ions were $\mathrm{MSA}^{-}$(methanesulphonate), $\mathrm{Cl}^{-}, \mathrm{NO}_{3}^{-}, \mathrm{SO}_{4}^{2-}$, $\mathrm{Na}^{+}, \mathrm{NH}_{4}^{+}, \mathrm{K}^{+}, \mathrm{Mg}^{2+}$, and $\mathrm{Ca}^{2+}$. Analytical accuracy of the measured ions is typically around $\pm 10 \%$, and with low analytical concentrations between \pm 20 and $25 \%$.

The procedure for analysing the daily TNy filter samples, which was done at the Alfred-Wegener Institute, included wetting of the filters by $100 \mu \mathrm{l}$ 2-propanol, soaking and shaking in $20 \mathrm{ml}$ milliQ water, followed by ultrasonic treatment for 15 minutes. The extracts were analysed subsequently by ion chromatography (IC) on a Dionex ICS 2000 identically equipped just as the FMI system, except the use of AG18/AS18 colums for anion analysis. In general, samples were analyzed for $\mathrm{MSA}^{-}, \mathrm{Cl}^{-}, \mathrm{Br}^{-}, \mathrm{NO}_{3}^{-}, \mathrm{SO}_{4}^{2-}$, oxalate $\left(\mathrm{C}_{2} \mathrm{O}_{4}^{2-}\right)$, $\mathrm{Na}^{+}, \mathrm{NH}_{4}^{+}, \mathrm{K}^{+}, \mathrm{Mg}^{2+}$, and $\mathrm{Ca}^{2+}$. The uncertainty was approximately $\pm 10 \%$ to $\pm 15 \%$ for the main components $\mathrm{MSA}^{-}, \mathrm{Cl}^{-}, \mathrm{Br}^{-}, \mathrm{NO}_{3}^{-}, \mathrm{SO}_{4}^{2-}, \mathrm{Na}^{+}$, and between $\pm 20 \%$ and $\pm 30 \%$ for the minor species $\mathrm{NH}_{4}^{+}, \mathrm{K}^{+}, \mathrm{Mg}^{2+}$, and $\mathrm{Ca}^{2+}$. Non-sea salt sulphate (nss- $\mathrm{SO}_{4}^{2-}$ ) mass concentrations, as well as chloride depletion were calculated using sodium as sea salt reference species (Wagenbach et al.

q The SDI data were run through the inversion code MICRON (Wolfenbarger and Seinfeld, 1990) to extract continuous mass size distributions for the measured ions. A successful inversion by MICRON requires information on the impactor collection characteristics, as well as on errors related to measurements and chemical analysis. The errors used in the MICRON inversions were typically $10 \%$ of the measured ion concentrations, but larger errors (20-30\%) were used when the concentration of measured ions were very low. The MICRON code takes the concentrations, as well as the errors of different ions in different impactor stages as an input. A discussion on how inverted size distributions de- 
146

147 1997).

148 Particle collection efficiency curves of the SDI stages for MICRON were ta-

pend on uncertainties in the concentration data can be seen in (Kerminen et al. ken from the calibrations made in the FMI aerosol laboratory (Maenhaut et al. 1996). The mass size distributions given by the MICRON were finally represented by a sum of log-normal modes. These were obtained using software developed by Winklmayr et al. (1990), modified later at the University of Gent, Belgium. The mass mean diameter of each mode, its geometric standard deviation, and the concentration of the chemical compound in the mode is obtained when the fitting procedure is done.

\section{Results and Discussion}

\subsection{Comparison of the SDI and TNy results}

The average ratio of the sulphate amount determined by the SDI compared to the TNy was 0.9. Lower respective ratios were observed during few samplings when the sulphate loading was extraordinary low (near or below $10 \mathrm{ng} \mathrm{m}^{-3}$ ). These lower ratios are most probably due to some uncertainties in chemical analysis of the individual SDI stages. The correlation between the SDI and TNy filter samplings for sulphate and sodium are shown in Figure 1. For sodium, the average SDI to TNy ratio was 0.6. Not only one explicit explanation for this quite low ratio could be addressed. The lower sodium concentration obtained from the SDI samples may be due to bounce off of sea salt particles inside the SDI impactor stages, or limitations in the chemical analyses. Sodium is divided in several stages in the SDI impactor, which may result larger errors in the chemical analyses, especially when the collected sea salt concentration is low. When comparing the SDI and TNy samples, the daily $\mathrm{TNy}$ samples were averaged over the 7 days SDI samplings, which further may increase uncertainty. Also the cut-off of the inlet is only a rough estimation, and it is depended on wind velocity, so sea salt particles larger than $7 \mu \mathrm{m}$ may have gone through it, and sampled with the TNy sampler. 
Although the sodium concentration obtained from the SDI samplings were lower than those obtained from the TNy samples, the correlation of sodium between both these devices was reasonably good. All the stages of individual SDI samplings were analysed in similar manner, so it can be assumed that even if there may be some uncertainty in the absolute sodium concentrations of the individual SDI samplings, the modal structure of mass size distributions is still reliable.

The low SDI to TNy ratios for $\mathrm{MSA}^{-}$and $\mathrm{NO}_{3}^{-}$can be due several reasons. 1) $\mathrm{MSA}^{-}$and nitrate typically show very low concentrations in the Antarctic atmosphere, and most of the SDI samples were collected during austral winter when their concentration can be assumed to be especially low. Errors in chemical analyses, which were discusses also in the case of sodium, may explain partly these low ratios. 2) The TNy results are combination of the Teflon and Nylasorb filter results, so it is possible that gaseous precursors, especially for nitrate, have absorbed on the Nylasorb filter. 3) The possible evaporation of $\mathrm{MSA}^{-}$and nitrate from the SDI impactor can not totally be ruled out. The low pressure especially in the lowest SDI stages can promote the dissociation of these species to gaseous phase, and cause the lower concentrations of these compounds in the SDI samples.

The upper impactor stage $(>8.5 \mu \mathrm{m})$ has been discarded from the later analysis of individual impactor stages, since particles larger than $7.0 \mu \mathrm{m}$ are greatly affected by the losses of the sampling line. However it has taken into account in MICRON runs, although large error has been used for the upper impactor stage when performing the MICRON runs.

The measurements showed three distinct episodes during austral winter. These episodes were 8.6-15.6 (Case I), 29.6-6.7 (Case II), and 21.7-27.7 (Case III) which all consisted one SDI sampling. In chapter 3.6 we will discuss more detailed of these episodes. 


\subsection{Particle number concentration and size distributions}

The measured total particle number concentration (above $0.3 \mu \mathrm{m}$ ) varied largely throughout the year (Figure 2). The average "background particle number concentration" was between 2000 and 3000 particles $\mathrm{dm}^{-3}$, but particle concentrations above 10000 particles $\mathrm{dm}^{-3}$ were also frequently observed. The time when particle concentration was enhanced lasted from few hours to several days. On the overall, the time when enhanced particle concentration was measured consist about one third of the measurements. As high particle number concentrations as 80000 particles $\mathrm{dm}^{-3}$ were measured during austral winter. There were also few cases when the particle number concentration was as low as 10 particles $\mathrm{dm}^{-3}$. On average $95 \%$ of the measured particles were found in the size range $0.3-1.0 \mu \mathrm{m}$. The Grimm OPC channels measuring particles larger than $4.0 \mu \mathrm{m}$ in diameter showed results only occasionally, and even then the concentration of particles larger than $4.0 \mu \mathrm{m}$ was less than 1 particles $\mathrm{dm}^{-3}$.

Total particle number concentration was measured also using a Condensation Particle Counter (CPC, model 3022A) at Neumayer station. Since the Grimm OPC measures only particles above $0.3 \mu \mathrm{m}$ in diameter, a direct comparison of these two measurement devices is not meaningful. However when comparing the total particle number concentration obtained from these two instruments, an estimation of how much particles above $0.3 \mu \mathrm{m}$ contribute to the total particle concentration can be made. Most of the time the total particle number concentration measured with the Grimm OPC was only few percent from those measured with the CPC. According to this, the majority of the measured aerosol particles were smaller than $0.3 \mu \mathrm{m}$ at Neumayer station. An exception was the extraordinarily high sea salt concentration case (see chapter 3.6), when concentrations measured with the Grimm OPC were $60 \%$ of those measured with the $\mathrm{CPC}$, and the Grimm OPC showed the highest particle number concentration during the campaign (80 000 particles $\mathrm{dm}^{-3}$ ).

Particle area- and volume size distributions were calculated from the obtained particle number concentration distributions. The calculated one day average particle size distributions were very similar during the whole year. An exception 
was the size distributions during February and December (Figure 3), when an increasing particle concentration was observed in the size fraction $0.3-0.4 \mu \mathrm{m}$. The increased particle number concentration in this size fraction is most probably due to sulphate particles produced during austral summer in the nearby oceans, which could also be seen from the mass size distributions of nss-sulphate (see next section). During June and July (Figure 3), when highest total particle concentrations were measured, the particle concentrations in the size fraction 0.3-0.4 $\mu \mathrm{m}$ were also elevated, but not as much as during austral summer months. The enhanced particle concentrations during June and July are due to higher sea salt loadings at the measurement site. Higher particle concentrations in the lower Grimm OPC channel are most probably due to high concentration of smaller sea salt particles, since during austral winter the production of secondary sulphate aerosol is in its minimum.

There was a gap near $1 \mu \mathrm{m}$ in the particle number distribution, and the maximum particle number concentration in the supermicron size range was observed in the size range 1.6-2.0 $\mu \mathrm{m}$. The geometric average of this size bin is near $1.8 \mu \mathrm{m}$, which can be estimated to be the center of this mode. There is also a mode below $1.0 \mu \mathrm{m}$. Since the Grimm OPC measures only particles above $0.3 \mu \mathrm{m}$, and since the concentration of sulphate was very low, except during February and December, it can be assumed that the majority of particles measured with the Grimm OPC during the measurement campaign were sea salt particles.

\subsection{Size-segregated chemistry}

The measured sodium and non-sea-salt sulphate (nss-sulphate) concentrations, as well as total sulphate concentrations obtained from the SDI measurements are shown in Figure 4. Nss-sulphate concentration was in its maximum during austral summer, and in its minimum during austral winter. The seasonal variation of nss-sulphate concentration in Antarctica is due to the enhanced production of secondary biogenic sulphate aerosol during austral summer in the nearby ocean. Similar seasonal variation of nss-sulphate has been observed in 
year round measurements at coastal stations in Antarctica (Jourdain and Legrand, 2002, Wagenbach et al., 1998, Rankin and Wolff, 2003; ,Jourdain and Legrand, 2001, Minikin et al., 1998; Weller and Wagenbach, 2007; Weller et al. 2008). The concentration of sodium did not show any clear seasonal variation, but its concentration varied throughout the year. By the end of July, a high sodium concentration was measured at NM. Elevated concentrations of sea salt particles (sodium) have been found during austral winter also in earlier studies (Wagenbach et al., 1998, Rankin and Wolff, 2003). However, one has to keep in mind that our system did not collect efficiently particles larger than $7 \mu \mathrm{m}$ in their aerodynamic diameter. During austral summer, when the sea ice extent is in its minimum, larger particles produced mechanically over the ocean near NM station have most probably reached the measurement site prior to their deposition, but they were not collected with our sampling devices. On average 49 $\%$ (range 14-95) of sodium and $40 \%$ (range 3-96) of chloride was found in the submicron size range during the measurements. Sulphate was found on average $79 \%$ (range 51-99) in the submicron size range.

Examples of mass size distributions of sea salt derived ions, sodium and chloride, are shown in Figure 5. The selected examples correspond to the selected episodes discussed more detailed in chapter 3.6, and they refer to episodes with different sea salt loadings. The sea salt ions, sodium and chloride, had two modes in the submicron size range. The lower mode centred between 0.2 and $0.3 \mu \mathrm{m}$, and the second one centred around $0.8 \mu \mathrm{m}$ in particle aerodynamic diameter. A part of the samples did not show the lowest submicron mode for chloride. The absence of the lowest chloride mode in these samples is due to the more efficient depletion of chloride from smaller sea salt particles. Usually, the dominant mode in the supermicron size range centred around $2 \mu \mathrm{m}$. Occasionally there was also a mode between 4 and $7 \mu \mathrm{m}$.

Figure 6 shows the mass size distributions of nss-sulphate during austral summer, and during austral winter. Nss-sulphate showed typically three modes, two in the submicron, and one in the supermicron size range. The dominant mode was the one peaked near $0.23 \mu \mathrm{m}$. The other two modes peaked around 
0.7 and $1.6 \mu \mathrm{m}$. Earlier size-segregated studies at coastal Antarctic stations showed similar modal structures for these compounds (Hillamo et al. 1998 Jourdain and Legrand, 2002; Rankin and Wolff, 2003)

\subsection{Comparison of the Grimm OPC measurements and filter samplings}

The particle volume concentrations calculated from the Grimm OPC measurements were compared to the total ion mass concentration obtained from the TNy samplings. Only those TNy samplings were used for comparison where minimum time of interruptions were occurred during the samplings, since the Grimm OPC was not shut down during bad weather conditions, or when possible local contamination occurred. The correlation between the particle volume and total ion concentration was good $\left(\mathrm{R}^{2}=0.86\right)$. However, the particle density can not be estimated based on these measurements, since the size resolution of the Grimm OPC is not good enough.

\subsection{Chemical processes modifying sea salt particles}

Figure 8a shows the degree of chloride depletion from the SDI samples. The chloride depletion is calculated based on the sea water content of sodium and chloride, so the calculated negative values resembles to excess chloride referring to sodium. During austral summer the chloride depletion was largest, about 70 $\%$ of chloride was depleted from the sea salt particles during February. This is expected, since the formation of secondary acidic gaseous compounds triggering the chloride depletion is largest during austral summer. The chloride depletion decreased sharply at the beginning of April, and the depletion was only 20-30 $\%$ most time of the local winter. One SDI sampling, referring to Case III, was an exception, showing excess chloride referring to sodium. The excess chloride indicates that depletion of sodium has been taking place during the formation of sea salt particles.

Figure $8 \mathrm{~b}$ shows the average chloride depletion for individual SDI stages throughout the measurement period (green). The chloride depletion was higher for the submicron particles, which was also seen from the mass size distributions. 
345 favours smaller particle size, which can explain this kind of behaviour. Figure 9

346 shows also the sulphate to sodium ratio for the SDI sampling for Case III, which

347 exhibited the largest sea salt content during the measurements with the lowest 348 chloride depletion. For this sample the sulphate to sodium ratio was much more 349 uniform over the entire size range 1 to $8.5 \mu \mathrm{m}$, and it was near the value of 0.07 351 Wagenbach, 2007). 


\subsection{Selected episodes}

The mass size distributions of sodium and chloride for the three selected episodes are presented in Figure 5 (Case I-III), and the calculated ten day backward air trajectories for these episodes in Figure 10.

Case I (8-15.6, 2010, SDI sampling 17): Efficient and straight transport of air masses from marine regions across the open water and sea ice. During this SDI sampling, sodium showed elevated concentration, indicating higher sea salt loading. Although sodium concentration was moderately high, it was not the maximum measured during the season. However, the size distribution of sodium and chloride showed that the majority of the sea salt mass was found in a larger particle size range $(4-7 \mu \mathrm{m})$. The backward air mass trajectories showed that the air masses arriving at the measurement site came most of the sampling time quite directly from the ocean, or coastal area, so the larger particles did not had time to settle prior to their arrival to the measurement site. There was some degree of sulphate depletion in this sample, so the collected sea salt was probably mixture of sea salt produced on the open ocean and on the freshly formed sea ice. Unfortunately, no Grimm OPC data is available during this sampling.

Case II (29.6-6.7, 2010, SDI sampling 20): Extremely low sea salt aerosol associated with transport from the Antarctic plateau indicate long range transport from potential source region to NM. This SDI sample corresponds to very low sea salt loading with sodium concentration as low as $5 \mathrm{ng} \mathrm{m}^{-3}$. The calculated backward trajectories showed that during this sampling period the air masses typically arrived from the continent, even from South Pole, to the measurement site. The mass size distributions of sodium and chloride for Case II (Figure 5b) showed that sodium and chloride were almost exclusively found in particles with aerodynamic diameter less than $1 \mu \mathrm{m}$. Particle number concentrations measured with the Grimm OPC showed values lower than 1000 particles $\mathrm{dm}^{-3}$ throughout the sampling time.

Case III (21-27.7, 2010, SDI sampling 23): Extraordinarily high sea salt concentrations caused by regional sources, most probably freshly formed sea ice. The highest sodium concentration during the season was measured during 
Case III (269 ng $\mathrm{m}^{-3}$ ), and the Grimm OPC showed particle number concentrations as high as 80000 particles $\mathrm{dm}^{-3}$. This sampling showed the most negative nss-sulphate values, indicating that large fraction of the sea salt particles were produced on the freshly formed sea ice. The backward trajectories showed that the air masses were circulated over the ocean near the coast before arriving at the measurement site. During this time of the season the ocean is frozen in this area, which also confirms the formation me0chanism of sea salt aerosol. As discussed earlier (section 3.5) this particular sample showed excess chloride compared to sodium (Figure 8b). The short transport distance to the measurement site, and the low concentrations of reactive gaseous compounds during this time of the season explains the low observed chloride depletion, and the depletion of sodium due to mirabilite crystallization further explains the observed excess chloride compared to sodium. As mentioned earlier, the excess chloride referred to sodium was found in both the supermicron and the submicron size range. The mass size distributions of sodium and chloride for this sample shows (Figure 5c) that the dominant sea salt mode was the one peaking near $0.8 \mu \mathrm{m}$. The larger sodium concentration in the submicron mode compared to the supermicron mode near $2.0 \mu \mathrm{m}$ may be due to deposition of larger particles prior to entering the measurement site. However the sea salt particles did not show any chloride depletion which was observed to some degree also during austral winter. This finding in combination with the high sea salt loading indicates that the transport time was short. Finally it appears that sea salt formation over sea ice favours smaller particle size compared to sea salt formation over open ocean.

\section{Conclusions}

Particle number concentration was measured concurrently with a Grimm OPC instrument at NM station, Antarctica in year 2010. Samples for chemical analysis were collected throughout the same time using a TNy filter sampler and a cascade impactor (SDI).

Particle number concentrations measured with the Grimm OPC showed lar- 
ge variations throughout the year. Largest measured particle number concentrations were 80000 particles $\mathrm{dm}^{-3}$ and lowest were below 10 particles $\mathrm{dm}^{-3}$. Especially during austral winter, the majority of the measured particles with the Grimm OPC were sea salt particles, while during austral summer the contribution of secondary sulphate particles was significant. Calculated total volume concentration obtained from the Grimm OPC measurements correlated well with total ion mass concentrations obtainded from the TNy samplings. Furthermore, similar modal structure could be seen from the Grimm OPC and SDI measurements.

According to the SDI measurements, about $50 \%$ of the sea salt aerosol mass is within the submicron size range. Below $0.2 \mu \mathrm{m}$ of particle aerodynamic diameter the amount of sea salt aerosol is negligible. In the supermicron size range sea salt aerosol was most pronounced during austral summer when sea ice extent is at minimum and nearby open water is frequently an efficient source region. Although sea salt aerosol concentrations are in their maximum during austral winter, the dominance of submicron sea salt aerosol indicate the dominance of long range transport.

The size segregated ionic composition of the aerosols revealed that sea salt particles had undergone distinct physico-chemical processes, either during different formation processes (open water as opposed to freshly formed sea ice), or during their transport to the measurement site (reaction with acidic gases or aerosol like nitric acid or sulphuric acid). For the latter, a high degree of chloride depletion was observed during austral summer, when the presence of these acidic gases exhibit their characteristic seasonal maximum. Chloride depletion decreased sharply with the advent of austral winter. Apart from chloride depletion, excess chloride (relating to sodium) was also detected in one SDI sample, indicating actually a sodium depletion by mirabilite formation on freshly formed sea ice areas (Rankin et al. 2000). Higher degree of chloride depletion was observed in the submicron size range.

Analysis of selected episodes showed that the concentration of sea salt particles, their modal structure, and their chemical composition is connected with 
${ }_{443}$ their source areas, their formation mechanisms, and local transport history.

\section{${ }_{444}$ Acknowledgements}

445 The authors would like to thank the technicians and scientist of the Neu446 mayer overwintering crew, whose outstanding commitment enabled achieving ${ }_{447}$ high quality aerosol records. We are thankful to NOAA Air Resources Labo${ }_{448}$ ratory for having made available the HYSPLIT trajectory calculation program 449 as well as all used input data files. This work was funded by the Academy of 450 Finland (contract 127411). 
451

${ }_{452}$ Draxler, R. R., Hess, G. D., 1998. An overview of the HYSPLIT4 modelling ${ }_{453}$ system for trajectoreis, dispersion and deposition. Aust. Met. Mag. 79, 295$454 \quad 308$.

455

\section{References}

Hall, J. S., Wolff, E. W., 1998. Causes of seasonal and daily variations in aerosol sea-salt concentrations at a coastal antarctic station. Atmon. Environ 32, 3669-3677.

Hara, K., Osada, K., Kido, M., Hayashi, M., Matsunaga, K., Iwasaka, Y., Yamanouchi, T., Hashida, G., Fukatsu, T., 2004. Chemistry and sea-salt particles and inorganic halogen species in Antarctica regions: Compositional differences between coastal and inland stations. J. Geophys. Res. 109, doi:10.1029/2004JD004713.

Hara, K., Osada, K., Kido, M., Matsunaga, K., Iwasaka, Y., Hashida, G., Yamanouchi, T., 2005. Variations of constituents of individual sea-salt particles at Syowa station, Antarctia. Tellus 57B, 230-246.

Hillamo, R., Allegrini, I., Sparapani, R., Kerminen, V.-M., 1998. Mass size distributions and precursor gas concentrations of major inorganic ions in Antarctic aerosols. In. J. Environ. Anal. Chem. 71, 353-372.

Jones, A. E., Weller, R., Minikin, A., Wolff, E. W., Sturges, W. T., McIntyre, H. P., Leonard, S. R., Schrems, O., Bauguitte, S., 1999. Oxidized nitrogen chemistry and speciation in the Antarctic troposphere. J. Geophys. Res. 104, $21,355-21,366$

Jourdain, A. E., Legrand, M., 2001. Seasonal variations of atmospheric dimetylsulfide, dimethylsulfoxide, sulfur dioxide, methanesulphonate, and non-seasalt sulfate aerosols at Dumont d'Urville (coastal Antarctica) (December 1998 to July 1999). J. Geophys. Res. 106, 14,391-14,408. 
Jourdain, B., Legrand, M., 2002. Year-round records of bulk and size-segregated aerosol composition and $\mathrm{HCl}$ and $\mathrm{HNO}_{3}$ levels in the Dumont d'Urville (coastal Antarctica) atmosphere: Implications for sea-salt aerosol fractionation in the winter and summer. J. Geophys. Res. 107, doi:10.1029/2002JD002471.

Jourdain, B., Preunkert, S., Cerri, O., Castebrunet, H., Udisti, R., Legrand, M., 2008. Year-round record of size-segregated aerosol composition in central Antarctica (Concordia station): Implications for the degree of fractionation of sea-salt particles. J. Geophys. Res. 113, doi:10.1029/2007JD009584.

Kerminen, V.-M., Aurela, M., Hillamo, R. E., Virkkula, A., 1997. "formation of particulate msa: deductions from size distribution measurements in the finnish arctic". Tellus 49B, 159-171.

Kerminen, V.-M., Teinilä, K., Hillamo, R., 2000. Chemistry of sea-salt particles in the summer Antarctic atmosphere. Atmos. Environ. 34, 2817-2825.

König-Langlo, G., J.C.King, P.Pettré, 1998. Climatology of the three coastal Antarctic stations Dumont d'Urville, Neumayer, and Halley. J. Geophys. Res. $103,10,935-10,946$.

Maenhaut, W., Hillamo, R., Mäkelä, T., Jaffrezo, J.-L., Bergin, J.-L., Davidson, M. H., 1996. A new cascade impactor for aerosol sampling with subsequent PIXE analysis. Nuclear Instruments and Methods B 109/110, 482-487.

Minikin, A., Legrand, M., Hall, J., Wagenbach, D., Kleefeld, C., Wolff, E., Pasteur, E. C., Ducroz, F., 1998. Sulfur-containing species (sulfate and methanesulfonate) in coastal Antarctic aerosol and precipitation. J. Geophys. Res. 103, 10,975-10,990.

Pakkanen, T. A., Hillamo, R. E., 2002. Comparison of sampling artifacts and ion balances for a Berner low-pressure impactor and a virtual impactor 7 , $129-140$.

Piel, C., Weller, R., Huke, M., Wagenbach, D., 2006. Atmospheric methane sulphonate and non-sea-salt sulfate records at the European Project for Ice 
Coring in Antarctica (EPICA) deep-drilling site in Dronning Maud Land, Antarctica. J. Geophys. Res. 111, doi:10,1029/2005JD006213.

Rankin, A., Wolff, E. W., 2003. A year-long record of size-segregated aerosol composition at Halley, Antarctica. J. Geophys. Res. 108, doi:10.1029/2003JD003993.

Rankin, A. M., Auld, V., Wolff, E. W., 2000. Frost flowers as a source of fractionated sea salt aerosol in the polar regions. Geophys. Res. Lett. 27, 3469-3472.

Teinilä, K., Kerminen, V.-M., Hillamo, R., 2000. A study of size-segregated aerosol chemistry in the Antarctic atmosphere. J. Geophys. Res. 105, 38933904 .

Virkkula, A., Teinilä, K., Hillamo, R., Kerminen, V.-M., Saarikoski, S., Aurela, M., Koponen, I. K., Kulmala, M., 2006. Chemical size distributions of boundary layer aerosol over the Atlantic Ocean and at an Antarctic site. J. Geophys. Res. 111, doi:10.1029/2004JD004958.

Wagenbach, D., Ducroz, F., Mulvaney, R., Keck, L., Minikin, A., Legrand, M., Hall, J. S., Wolff, E. W., 1998. Sea-salt aerosol in coastal Antarctic regions. J. Geophys. Res. 103, 10,961-10,974.

Wagenbach, D., Görlach, U., Moser, K., Münnich, K., 1988. Coastal Antarctic aerosol: the seasonal pattern of its chemical composition and radionuclide content. Tellus 40B, 426-436.

Weller, R., Wagenbach, D., 2007. Year-round chemical aerosol records in continental Antarctica obtained by automatic samplings. Tellus 59, 755-765.

Weller, R., Wagenbach, D., Legrand, M., Elsässer, C., Tian-Kunze, X., KönigLanglo, G., 2011. Continuous 25-yr aerosol records at coastal Antarctica-I: inter-annual variability of ionic compounds and links to climate indices. Tellus 63B, 901-919. 
${ }_{531}$ Weller, R., Wöltjen, J., Piel, C., Resenberg, R., Wagenbach, D., König-Langlo,

532 G., Kriews, M., 2008. Seasonal variability of crustal and marine trace elements

${ }_{533}$ in the aerosol at Neumayer station, Antarctica. Tellus 60B, 742-752.

${ }_{534}$ Winklmayr, W., Wang, H.-C., John, W., 1990. Twomey algorithm to the inver-

535 sion of cascade impactor data. Aerosol. Sci. Technol. 13, 322-331.

536 Wolfenbarger, J. K., Seinfeld, J. H., 1990. Inversion of aerosol size distribution 537 data. J. Aerosol. Sci. 21, 227-247.

538 Wolff, E., Legrand, M. R., Wagenbach, D., 1998. Coastal Antarctic aerosol and 539 snowfall chemistry. J. Geophys. Res. 103, 10,927-10,934.

540 Wolff, E. E., Rankin, A. M., Röthlisberger, R., 2003. An ice core indicator of An541 tarctic sea ice production. Geophys. Res. Lett. 30, doi:10,1029/2003GL018454. 


\section{Figure captions}

Figure 1. Correlations between measured sulphate and sodium concentrations between the SDI and TNy samplings.

Figure 2. Measured total particle number concentration from the Grimm OPC during the campaign.

Figure 3. Average number-, area-, and volume distributions during February and December (austral summer)and June and July (austral winter). Notice that the particle number concentration distributions are shown with a logarithmic y scale.

Figure 4. Total sulphate and sodium concentrations, as well as calculated non sea salt concentrations obtained from the SDI samples during the campaign. The negative nss-sulphate concentrations indicates that fractionation of sea salt has been taking place during its formation

Figure 5. Examples of mass size distributions of sodium and chloride during the selected episodes.

Figure 6. Examples of mass size distributions of nss-sulphate during austral summer and austral winter.

Figure 7. Correlation between total ion mass from the TNy samples and particle volume concentration calculated from the Grimm OPC measurements.

Figure 8. Total chloride depleted from the SDI samplings, and averaged chloride depletion from individual SDI stages during the campaign. The green histogram shows average chloride depletion from individual SDI stages over the whole period and the violet histogram chloride depletion during selected episode (Case III). The observed negative values indicate that sodium content in sea salt particles deviates from the sea water composition.

Figure 9. Average sulphate to sodium ratios from individual SDI stages during austral winter (blue) and from selected episode (red, Case III). K1 is the sea water sulphate to sodium ratio and $\mathrm{k} 2$ is the sulphate to sodium ratio observed in earlier measurements at Neumayer. Values lower than $\mathrm{k} 1$ indicates that fractionating of sea salt has been taking place.

Figure 10. Calculated 10-days backward air mass trajectories for the selected episodes. 


\section{Sulphate}

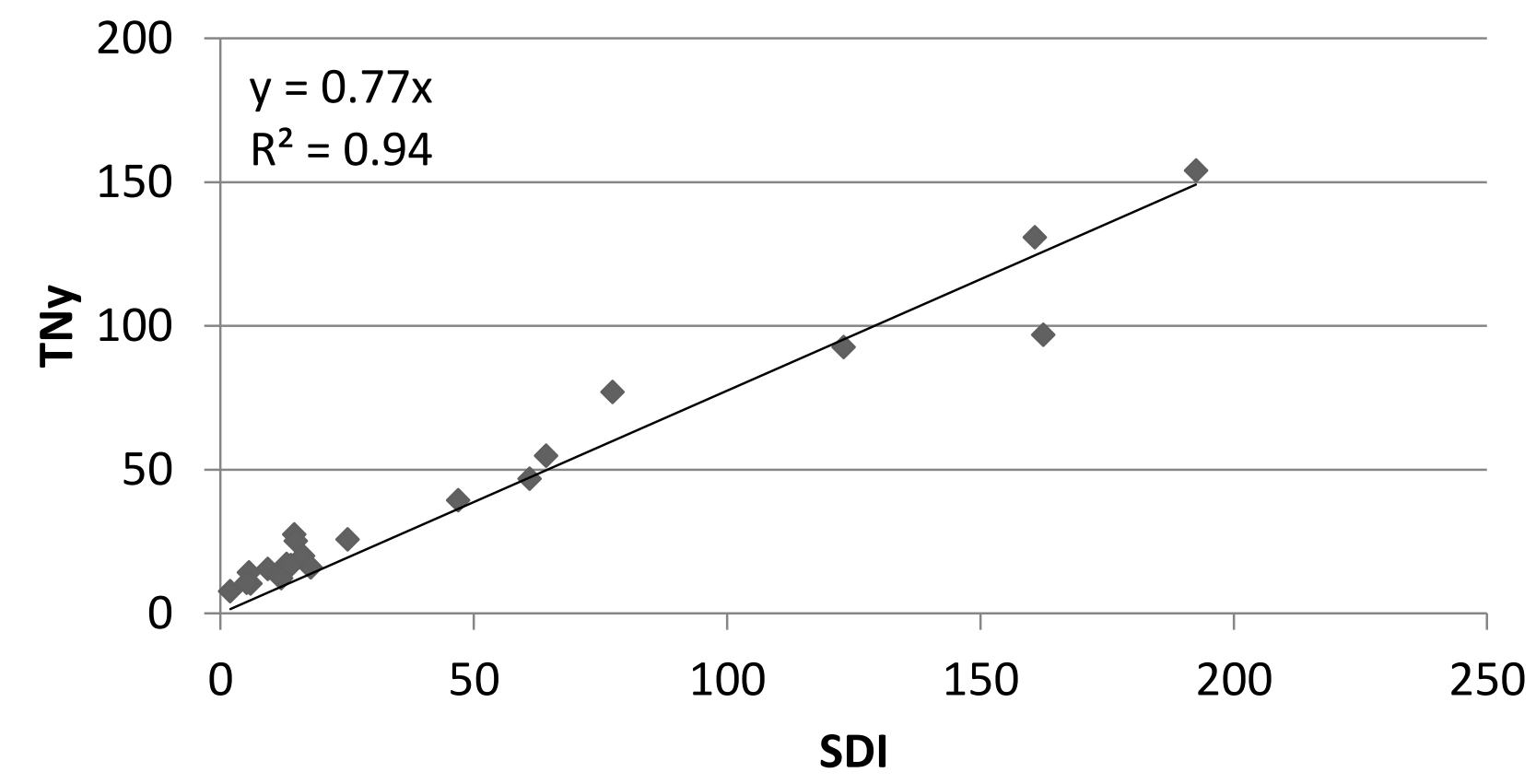

Sodium

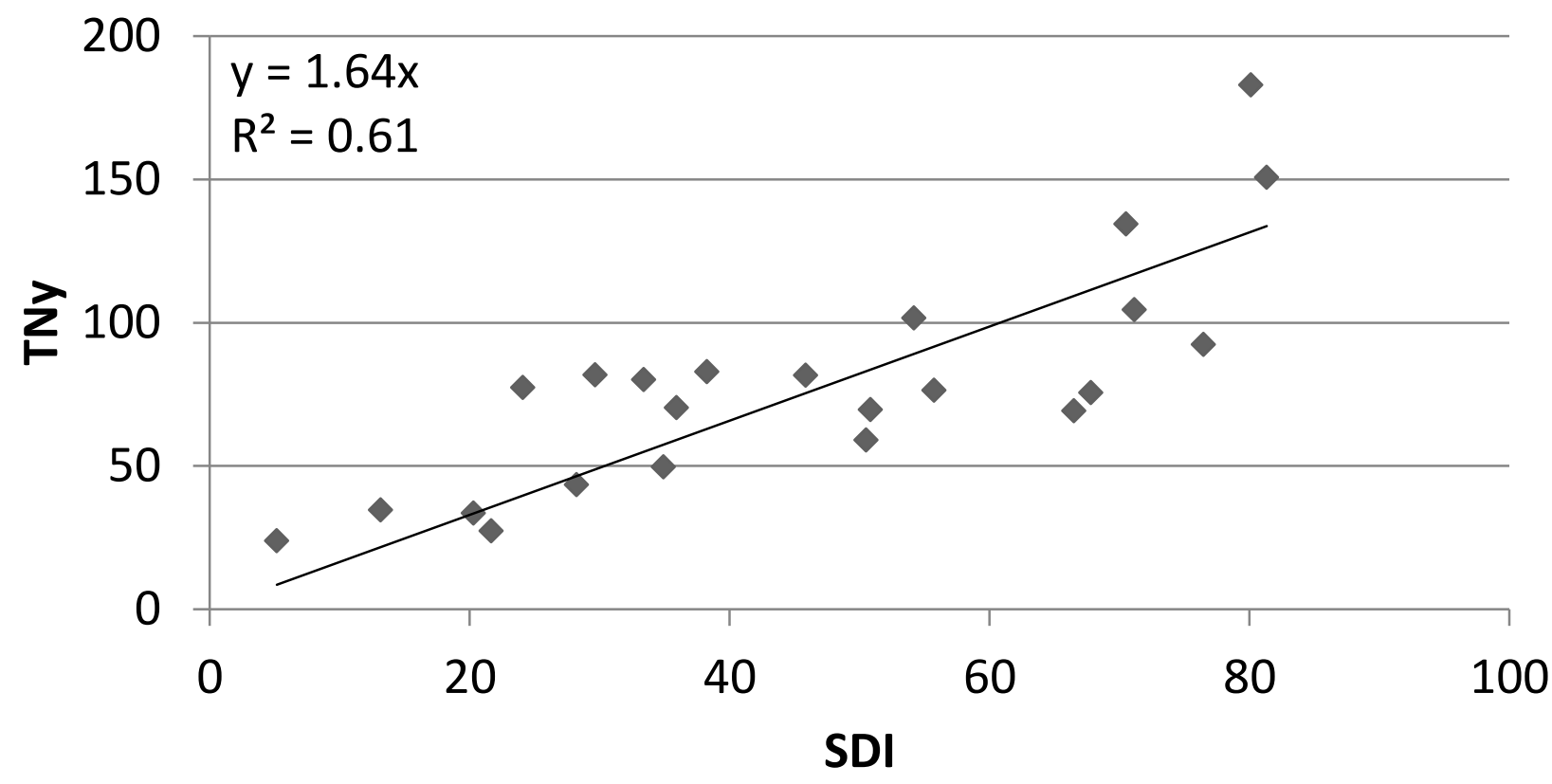




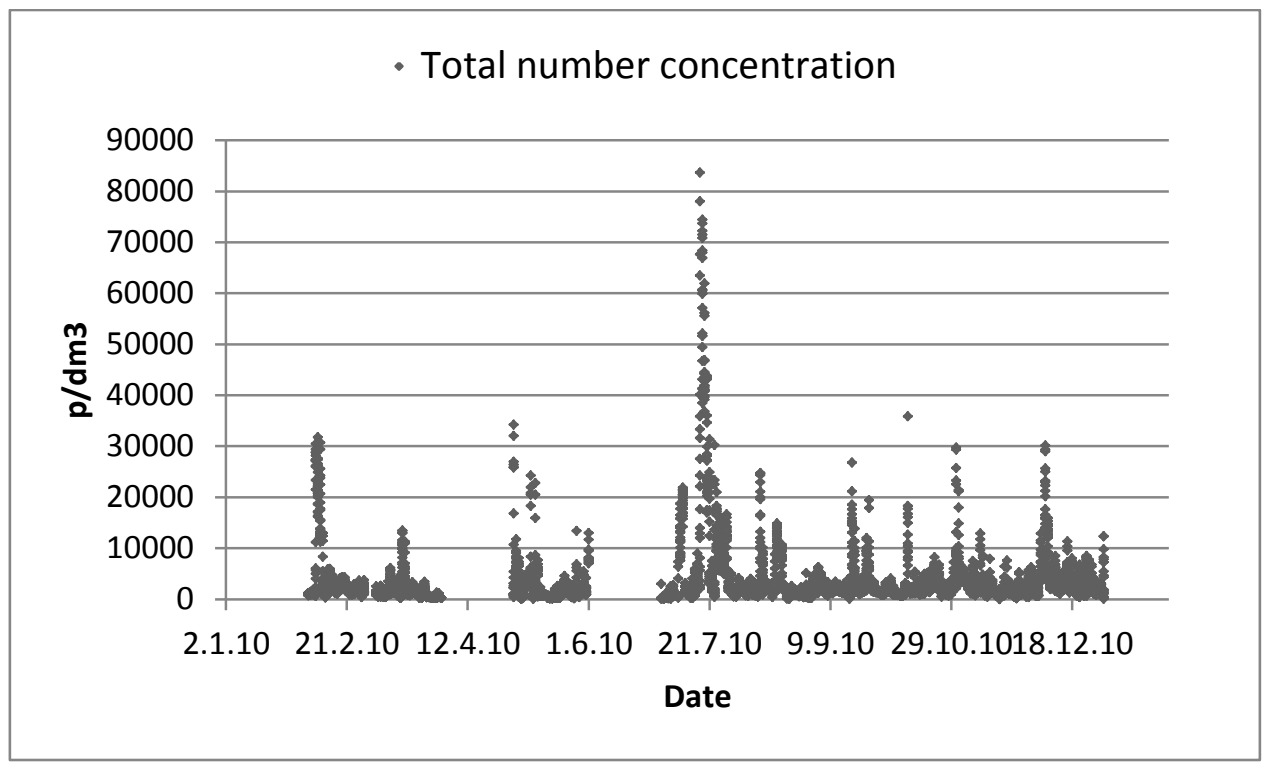

Figure 2 

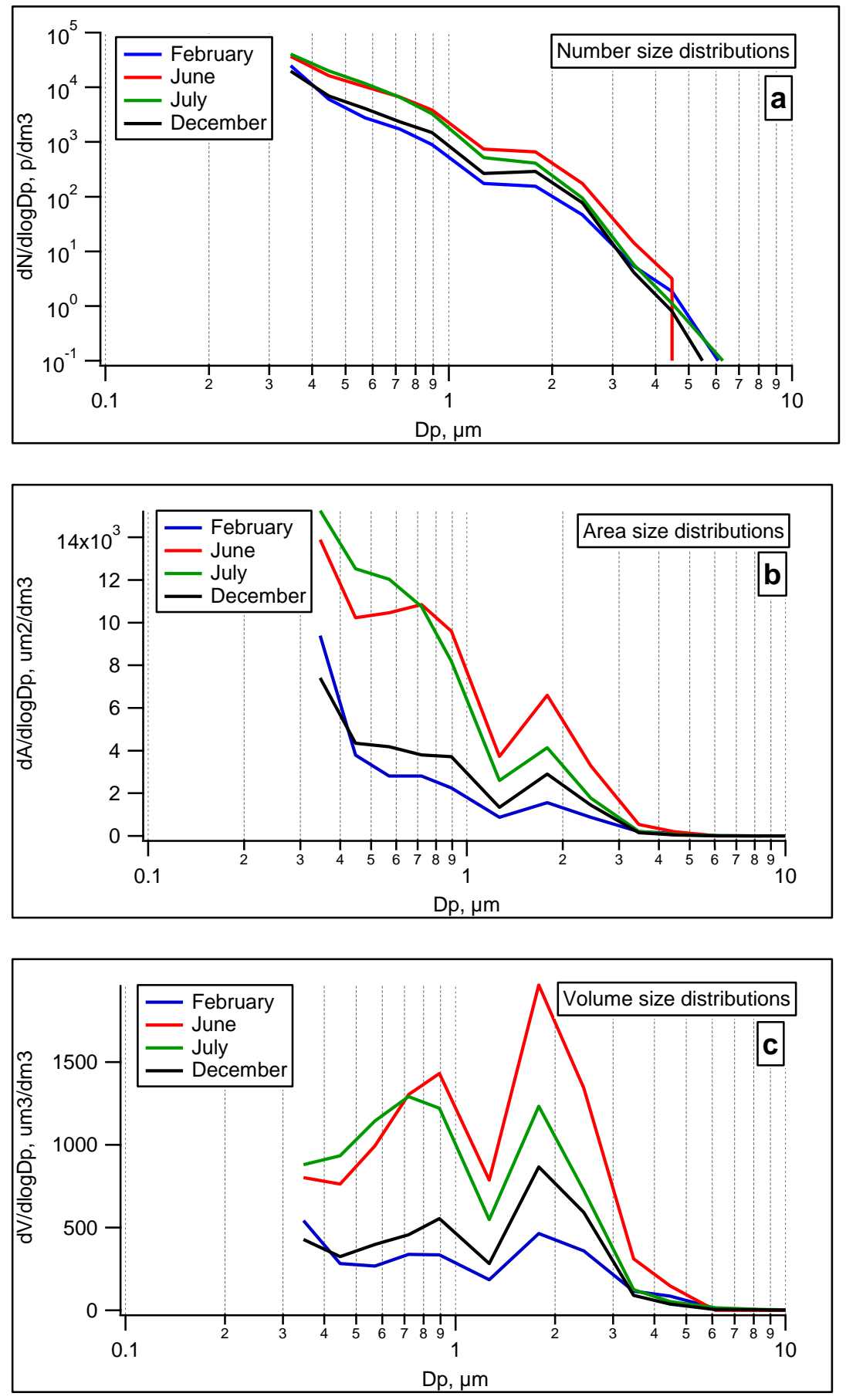


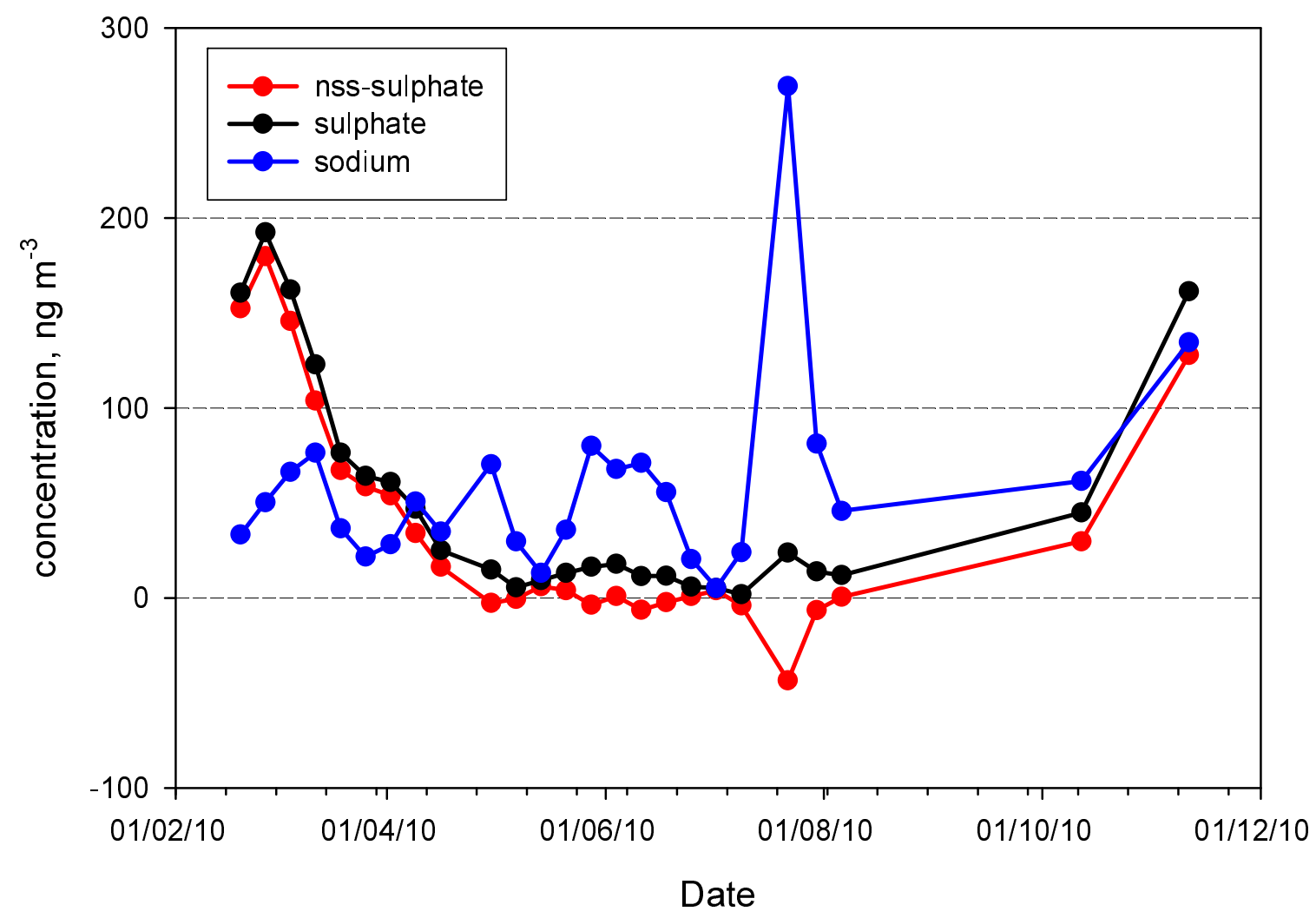

Figure 4 

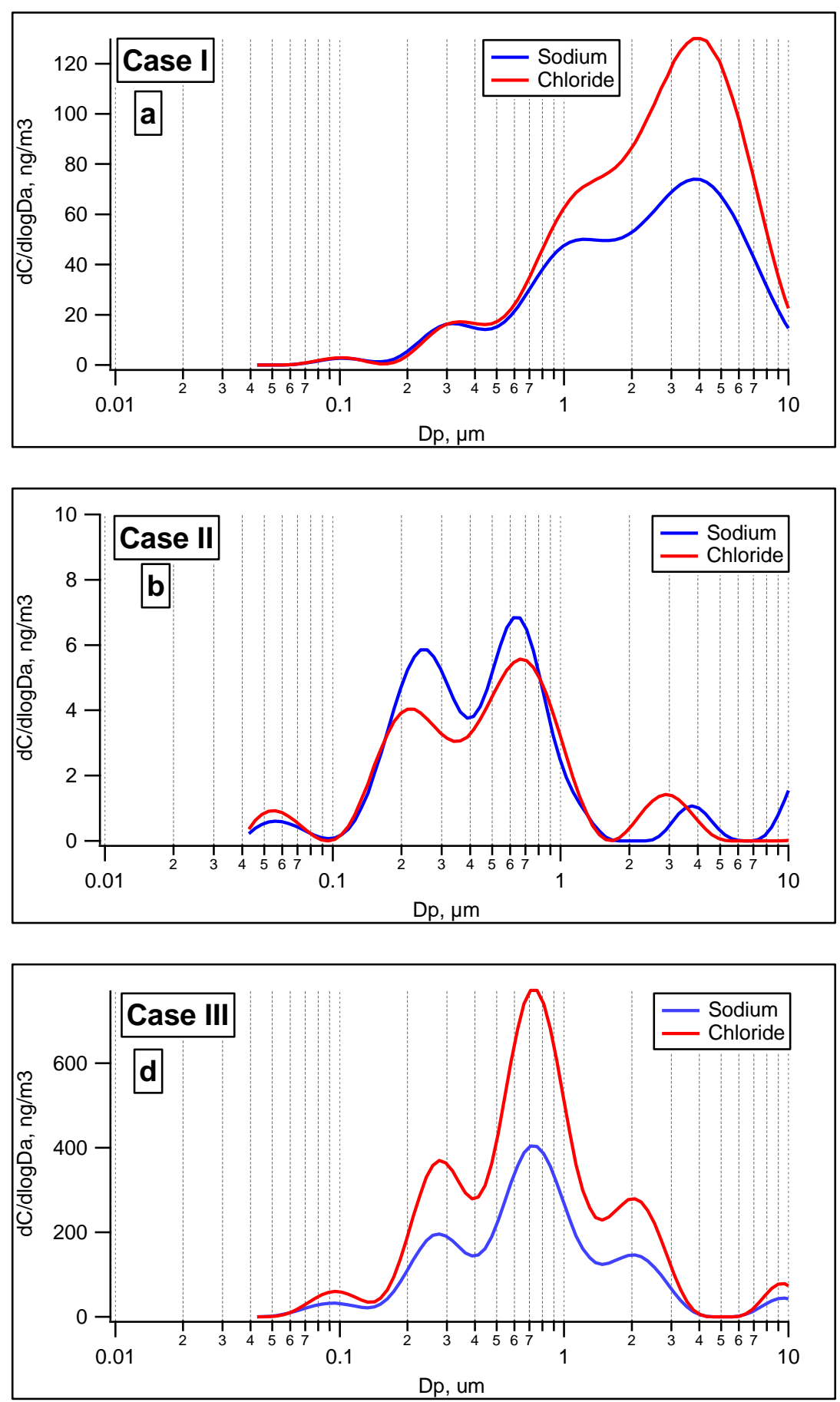

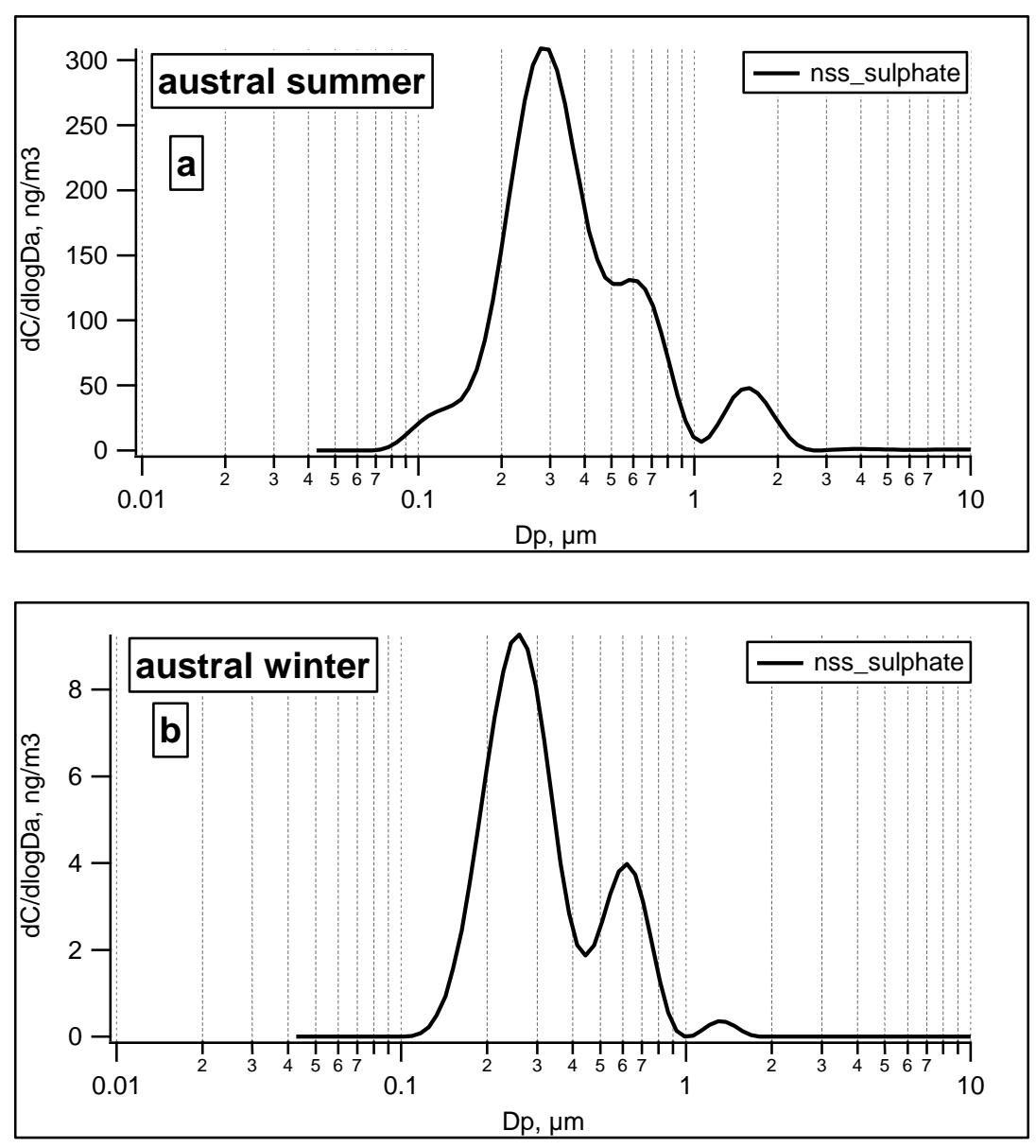


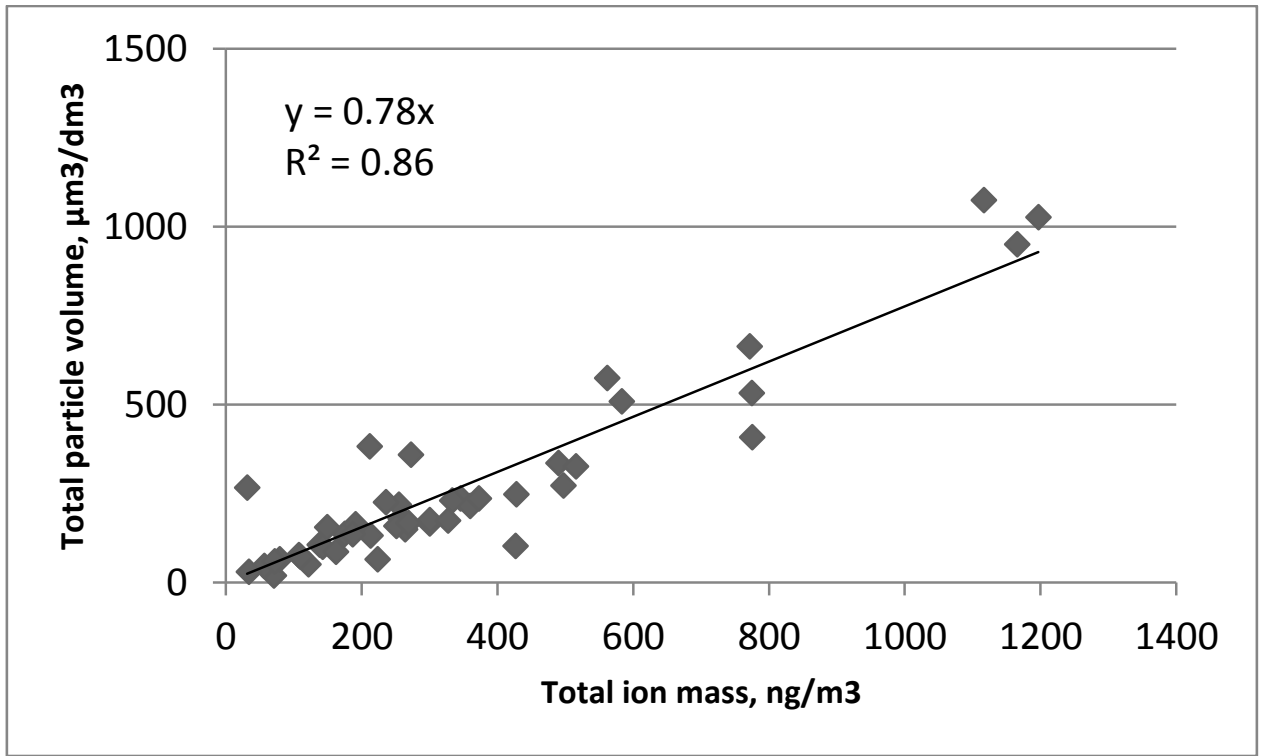



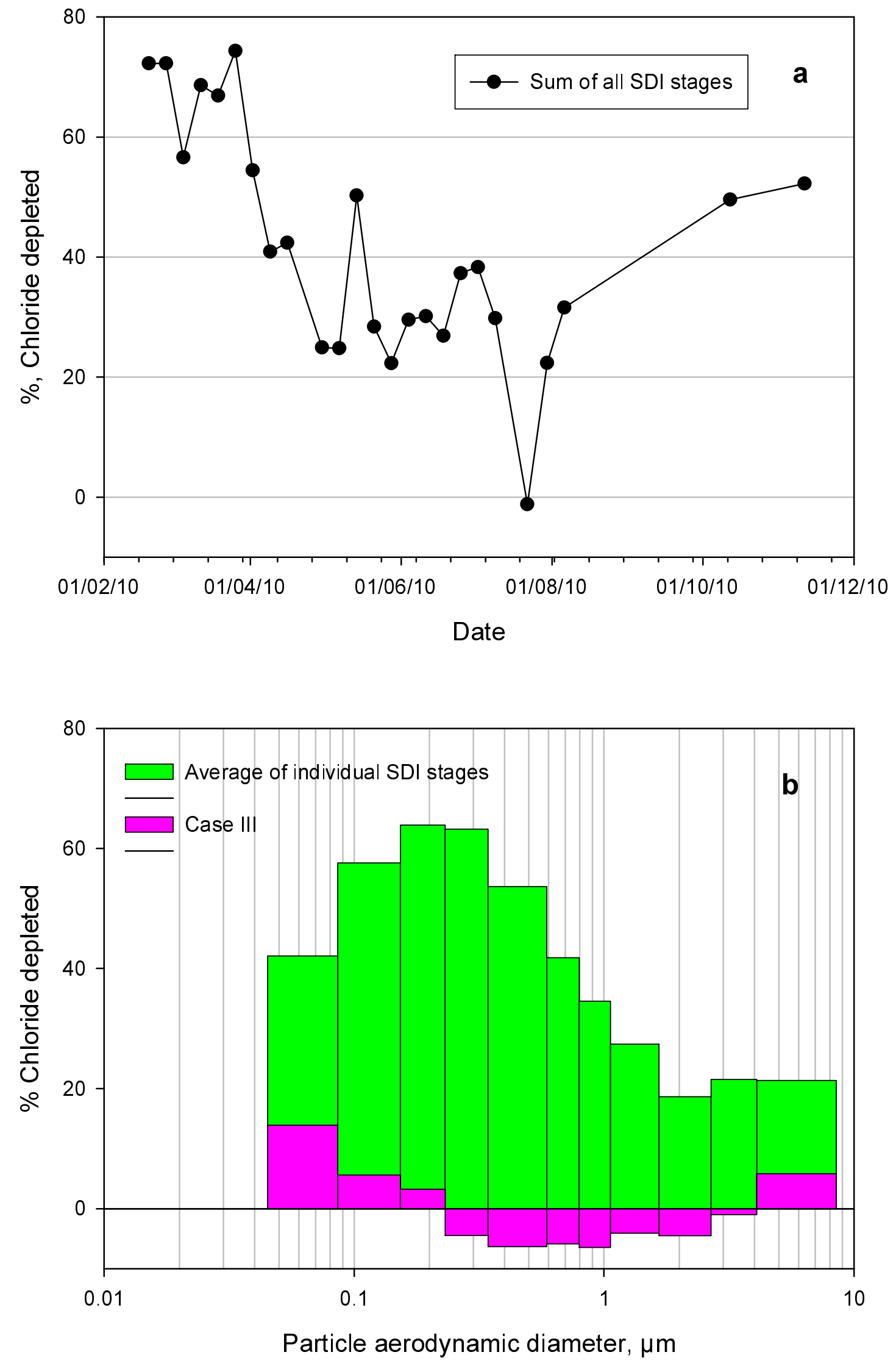


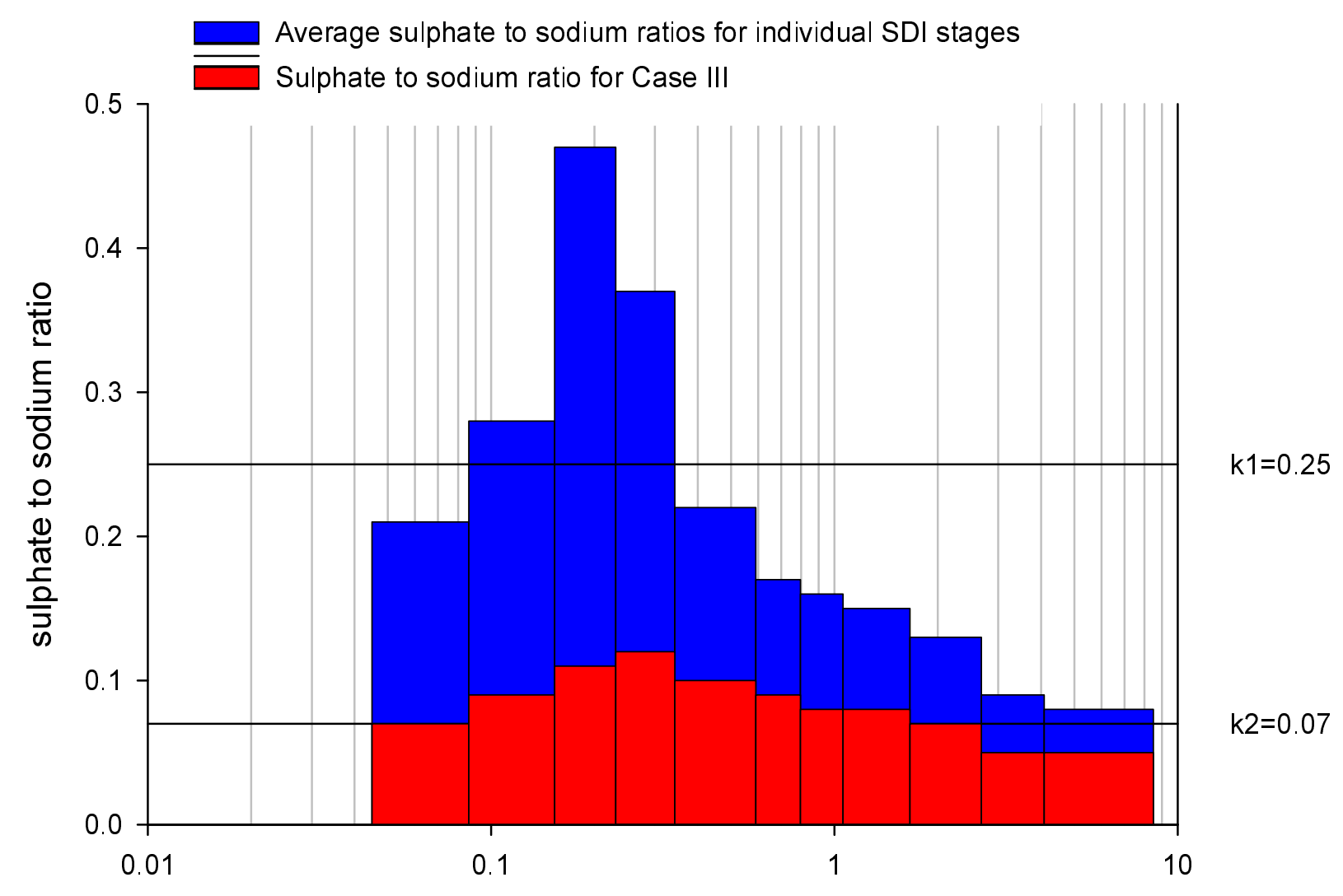

Particle aerodynamic diameter, $\mu \mathrm{m}$ 


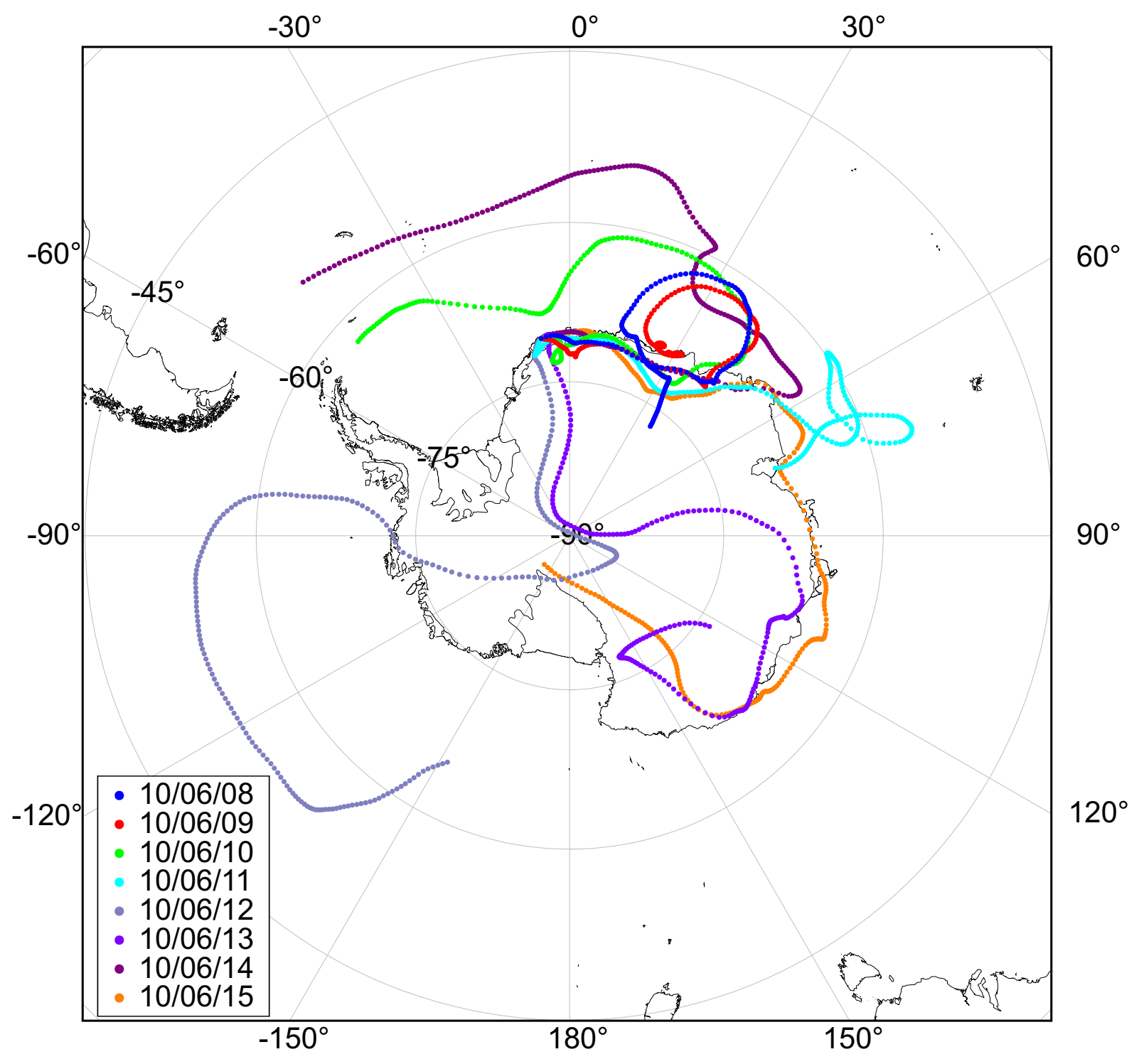




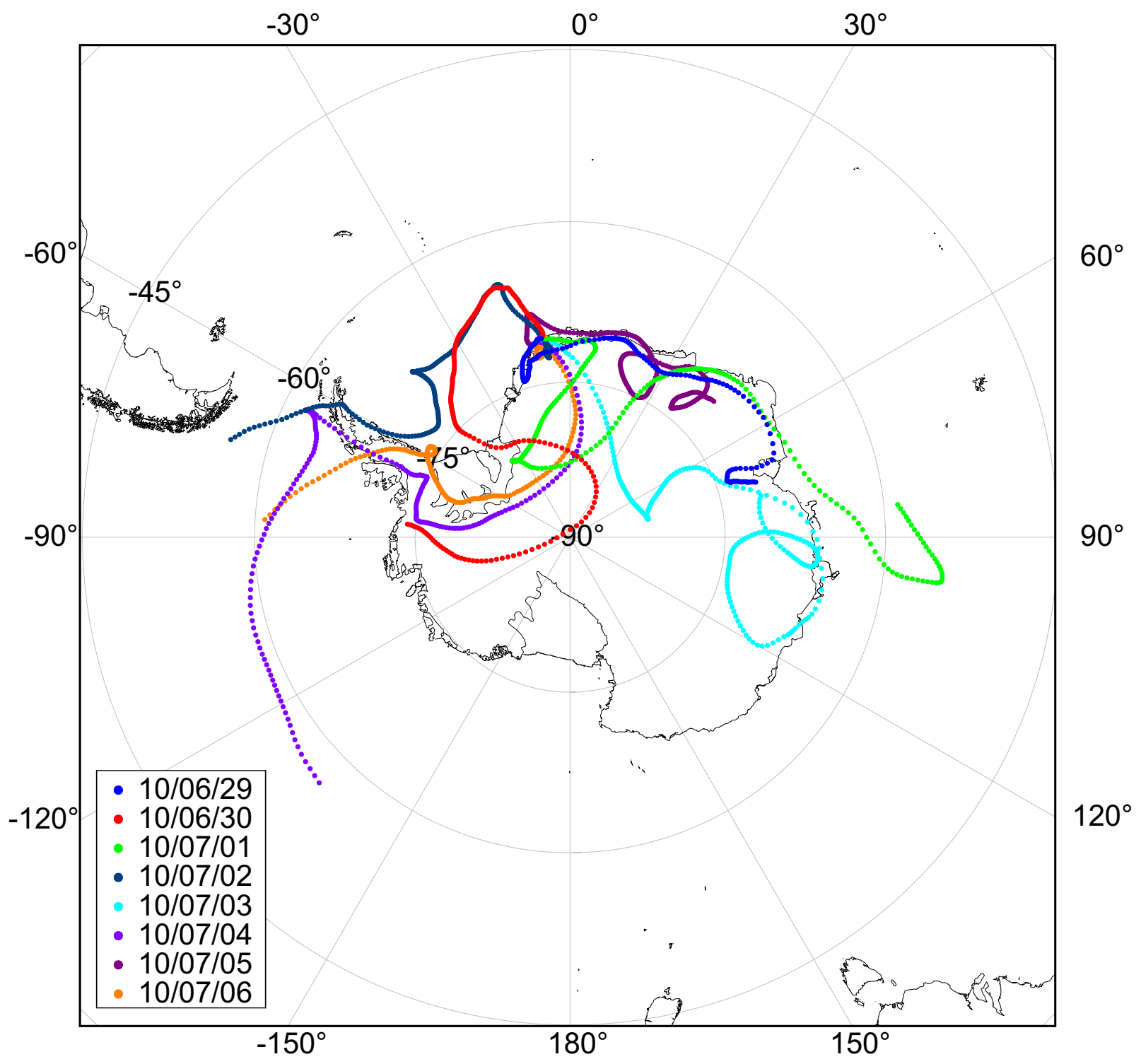




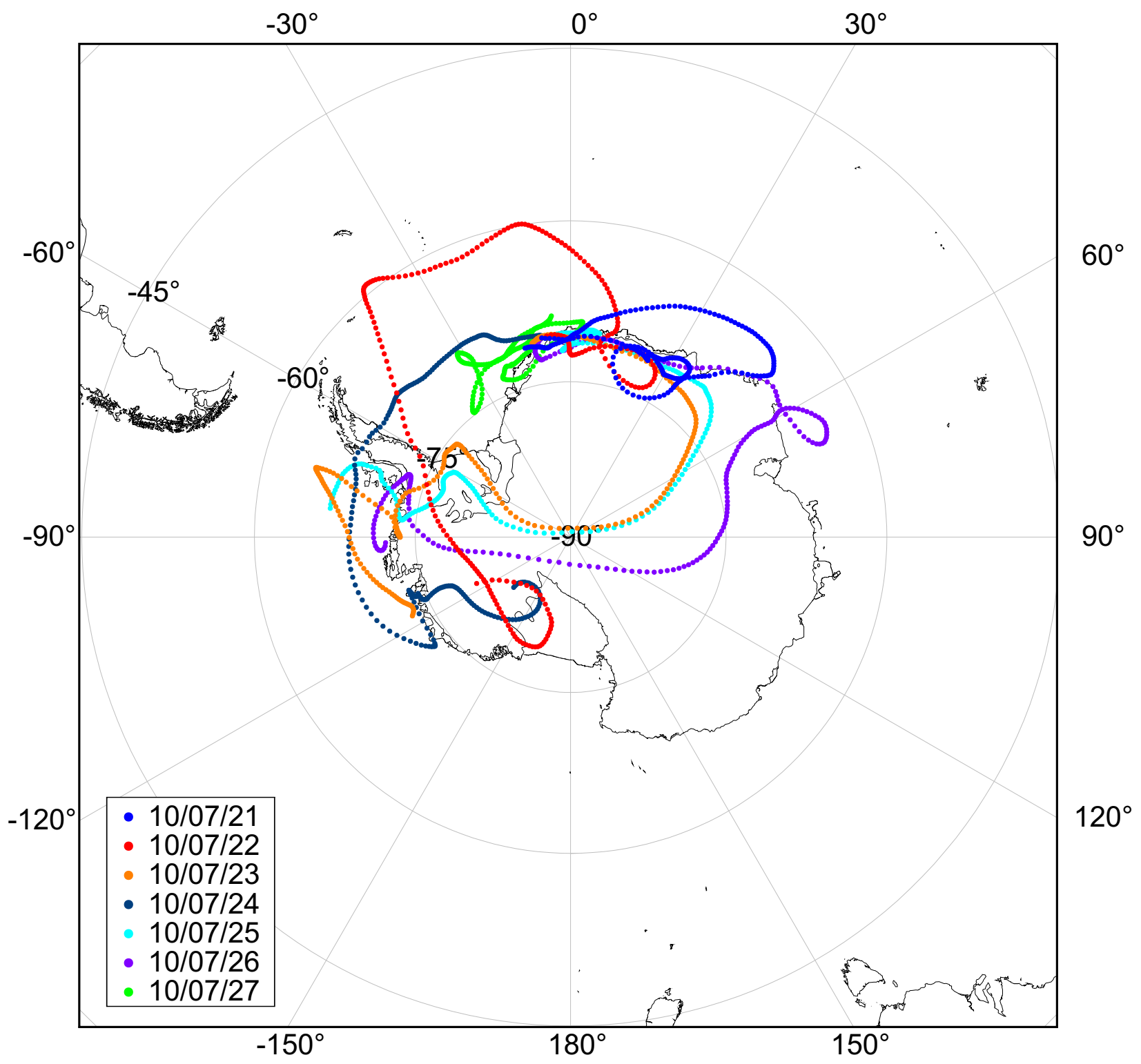

